\title{
Implementasi Sistem Informasi Monitoring Kendaraan Dinas Terintegrasi Pada Bank Indonesia Lhokseumawe
}

\author{
Mutasar $^{1}$, Novia Hasdyna ${ }^{2}$, Akbar Arafat ${ }^{3}$ \\ 1,2,3Program Studi Teknik Informatika, Universitas Islam Kebangsaan Indonesia \\ 1'mutasarstmik@gmail.com , ${ }^{2}$ noviahasdyna@gmail.com, ${ }^{3}$ akbarganto@gmail.com
}

\begin{abstract}
A monitoring system is needed to monitoring vehicle's daily activities at Bank Indonesia Lhokseumawe. The management of vehicle's daily activities in the Representative Office of Bank Indonesia Lhokseumawe is still using manual handwritting's records on some books, which is making it difficult to retrieve the required data quickly and accurately. To assist in carrying out the objection given, the authors designed an integrated information system which capable to monitoring vehicle's daily activities. The Information system based on web and gps for android.
\end{abstract}

Keyword: Information System, Monitoring Vehicle's, Web, Php

\section{Introduction}

Perkembangan teknologi informasi yang pesat semakin memudahkan manusia dalam memperoleh data dan informasi [1]. Kemajuan teknologi komputer dan informasi membawa pengaruh yang cukup besar dalam kinerja pengolahan data dan penyajian informasi pada suatu instansi pemerintahan maupun swasta [2]. Salah satu cara untuk meningkatkan kinerja pengolahan data adalah dengan adanya sistem informasi sehingga data yang diolah akan memberikan informasi yang akurat [3].

Sistem informasi merupakan suatu sistem yang menyediakan informasi untuk manajemen dalam mengambil keputusan dan juga untuk menjalankan operasional perusahaan [4]. Sistem informasi juga tidak hanya menjanjikan data yang diperoleh akurat tetapi juga meningkatkan kinerja pada perusahaan tersebut [5]. Monitoring merupakan kegiatan mengamati secara seksama suatu keadaan atau kondisi, termasuk juga perilaku atau kegiatan tertentu, dengan tujuan agar semua data masukan atau informasi yang diperoleh dari hasil pengamatan tersebut dapat menjadi landasan dalam mengambil keputusan untuk tindakan selanjutnya yang diperlukan [6]. Kendaraan Dinas merupakan Barang Milik Negara/Daerah berupa kendaraan bermotor yang digunakan oleh Pejabat Negara, pegawai Aparatur Sipil Negara, anggota Tentara Nasional Indonesia (TNI), dan anggota Kepolisian Negara Republik Indonesia (Polri) untuk melaksanakan tugas dan fungsi pada jabatan yang diembannya [7].

Saat ini manajemen kendaraan dinas di Kantor Perwakilan Bank Indonesia Lhokseumawe masih menggunakan pencatatan manual yang ditulis tangan pada buku-buku sehingga menyulitkan dalam mengumpulkan data-data yang dibutuhkan karena banyaknya jenis buku dan sering kali ditemui tulisan yang tidak terbaca ataupun terdapat kesalahan dalam penulisan data. Selain itu, diakhir bulan pencatatan kendaraan, baik itu penggunaan, pembelian bahan bakar, dan pemeliharaan harus dikumpulkan dan direkapitulasi ulang dengan mengetik kembali data yang telah dicatat dari buku-buku laporan ke dalam Microsoft Office (Word dan Excel), setelah itu baru dapat dilaporkan kepada Kepala Unit untuk dilanjutkan kepada Pimpinan untuk disetujui agar dapat dilakukan pembayaran.

Pada penelitian ini mengimplementasikan sistem informasi monitoring kendaraan dinas yang dapat memberikan kontribusi dalam membantu menyelesaikan permasalahan yang ada dan mempermudah dalam mengumpulkan informasi terkait kendaraan dinas di Kantor Perwakilan Bank Indonesia Lhokseumawe.

\section{Research Method}

Pada penelitian ini, metodologi yang dipakai adalah metode observasi dan wawancara. Pada saat melakukan pengamatan/observasi terdapat banyak buku pencatatan dari setiap jenis kendaraan dinas, baik catatan penggunaan, pembelian bahan bakar, dan catatan pemeliharaan kendaraan. Pada tahapan wawancara, metode ini dilakukan dengan mewawancarai langsung kepada pegawai yang terkait dengan operasional kendaraan dinas di Bank Indonesia Lhokseumawe. Berikut diagram alir penelitian seperti pada gambar 1. 


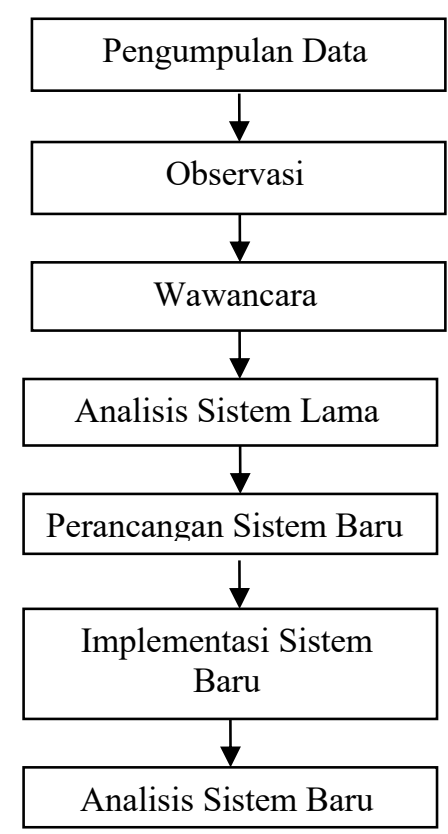

Gambar 1. Diagram Alir Penelitian

\subsection{Flowmap}

Berikut flowmap diagram sistem informasi pada penelitian ini seperti pada gambar 2.

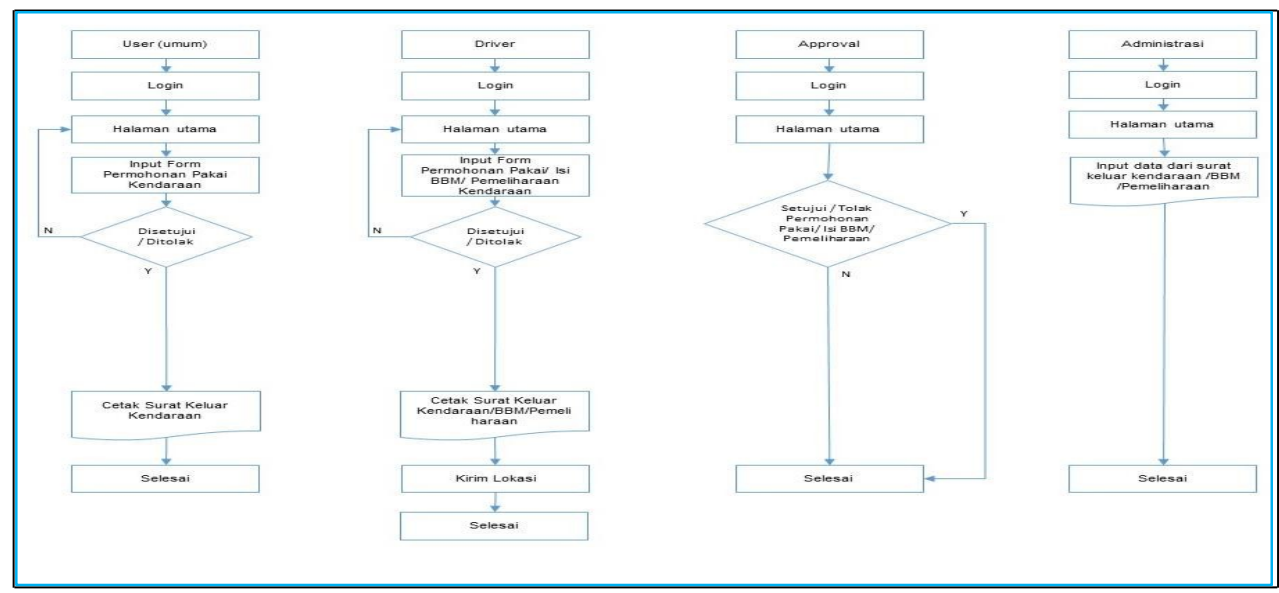

Gambar 2. Flowmap Sistem Informasi Monitoring Kendaraan Dinas

Adapun pada gambar 2 diatas, terdapat empat entitas yaitu user, driver, approval dan administrasi. Setiap entitas memiliki hak akses masing-masing.

\subsection{Sistem Informasi}

Sistem informasi dapat didefinisikan sebagai "Suatu sistem yang dibuat oleh manusia yang terdiri dari komponen-komponen dalam organisasi untuk mencapai suatu tujuan yaitu menyajikan informasi" selain itu dapat juga di definisikan sebagai "Sekumpulan prosedur organisasi yang pada saat dilaksanakan akan memberikan informasi bagi pengambil keputusan dan atau untuk mengendalikan organisasi" [8]. Kualitas dari suatu informasi (quality of information) tergantung dari tiga hal, yaitu informasi harus akurat (accurate), tepat pada waktunya (timeliness) dan relevan (relevance).

Nilai dari informasi (value of information) ditentukan dari dua hal, yaitu manfaat dan biaya mendapatkannya. Suatu informasi dikatakan bernilai bila manfaatnya lebih efektif dibandingkan dengan biaya mendapatkannya. Akan tetapi perlu diperhatikan bahwa informasi yang digunakan di dalam suatu sistem informasi umumnya digunakan untuk beberapa kegunaan [9]. 


\subsection{Monitoring}

Monitoring merupakan suatu kegiatan mengamati secara seksama suatu keadaan atau kondisi, termasuk juga perilaku atau kegiatan tertentu, dengan tujuan agar semua data masukan atau informasi yang diperoleh dari hasil pengamatan tersebut dapat menjadi landasan dalam mengambil keputusan tindakan selanjutnya yang diperlukan [10].

\section{Result and Analysis}

a. Context Diagram

Diagram Konteks adalah sebuah diagram sederhana yang menggambarkan hubungan antara entiti luar, masukan dan keluaran dari sistem ini seperti pada gambar 3.

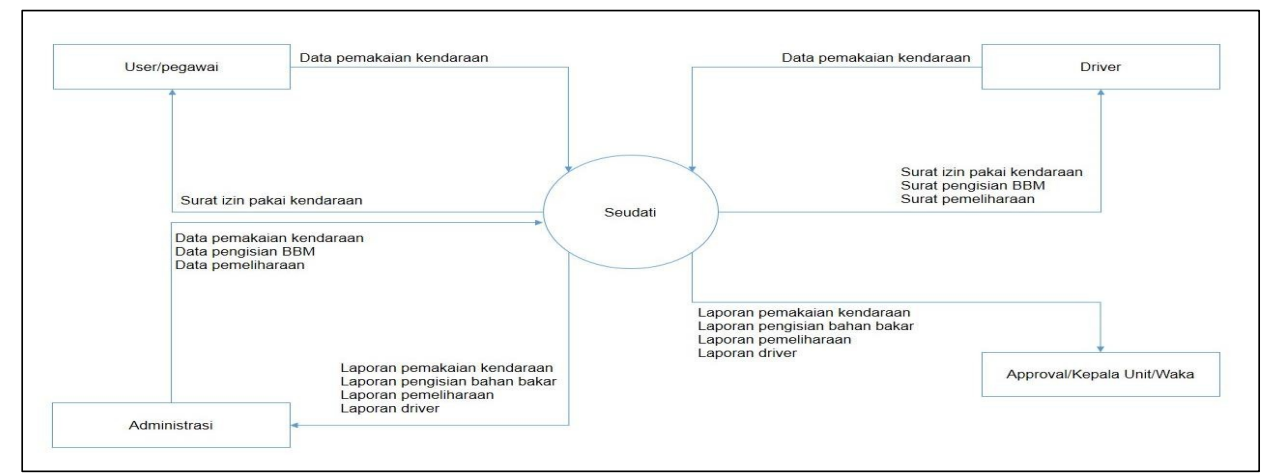

Gambar 3. Context Diagram

Pada context diagram terdapat empat entitas. User/pegawai, driver, administrasi dapat mengelola data pemakaian kendaraan. Administrasi dapat mengelola data pemakaian kendaraan, data pengisian bahan bakar dan data pemeliharaan. Pada bagian approval/Kepala Unit dapat menerima informasi/laporan berupa laporan pemakaian kendaraan, laporan pengisian bahan bakar, laporan pemeliharaan dan laporan driver.

\subsection{Data Flow Diagram (DFD)}

Data Flow Diagram (DFD) merupakan suatu model logika atau proses yang dibuat untuk menggambarkan dari mana asal data dan kemana tujuan data yang keluar dari sistem, dimana data disimpan, proses apa yang menghasilkan data tesebut dan interaksi antar data yang disimpan dan proses yang terjadi pada data tersebut. DFD menggambarkan penyimpanan data dan proses yang mentransformasikan data. DFD menunjukan hubungan antara data pada sistem dan proses pada sistem seperti pada gambar 4 .

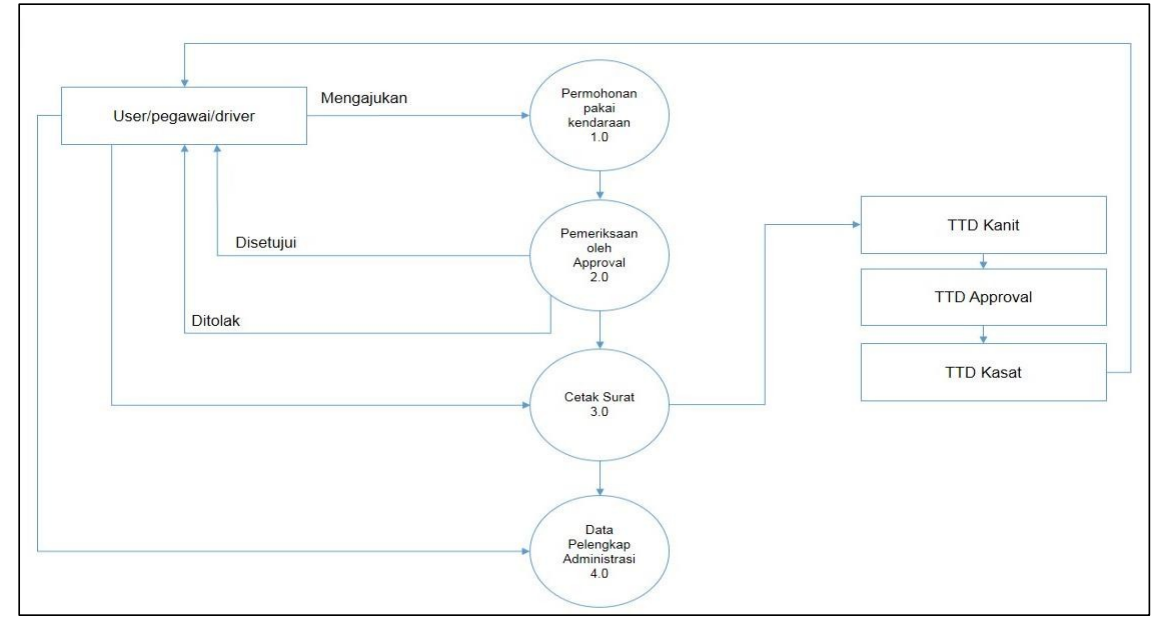

Gambar 4. Data Flow Diagram

\section{3. Activity Diagram}

Rancangan aliran aktivitas atau aliran kerja dalam Sistem Monitoring Kendaraan Dinas Terintegrasi yang akan dijalankan seperti pada gambar 5. 


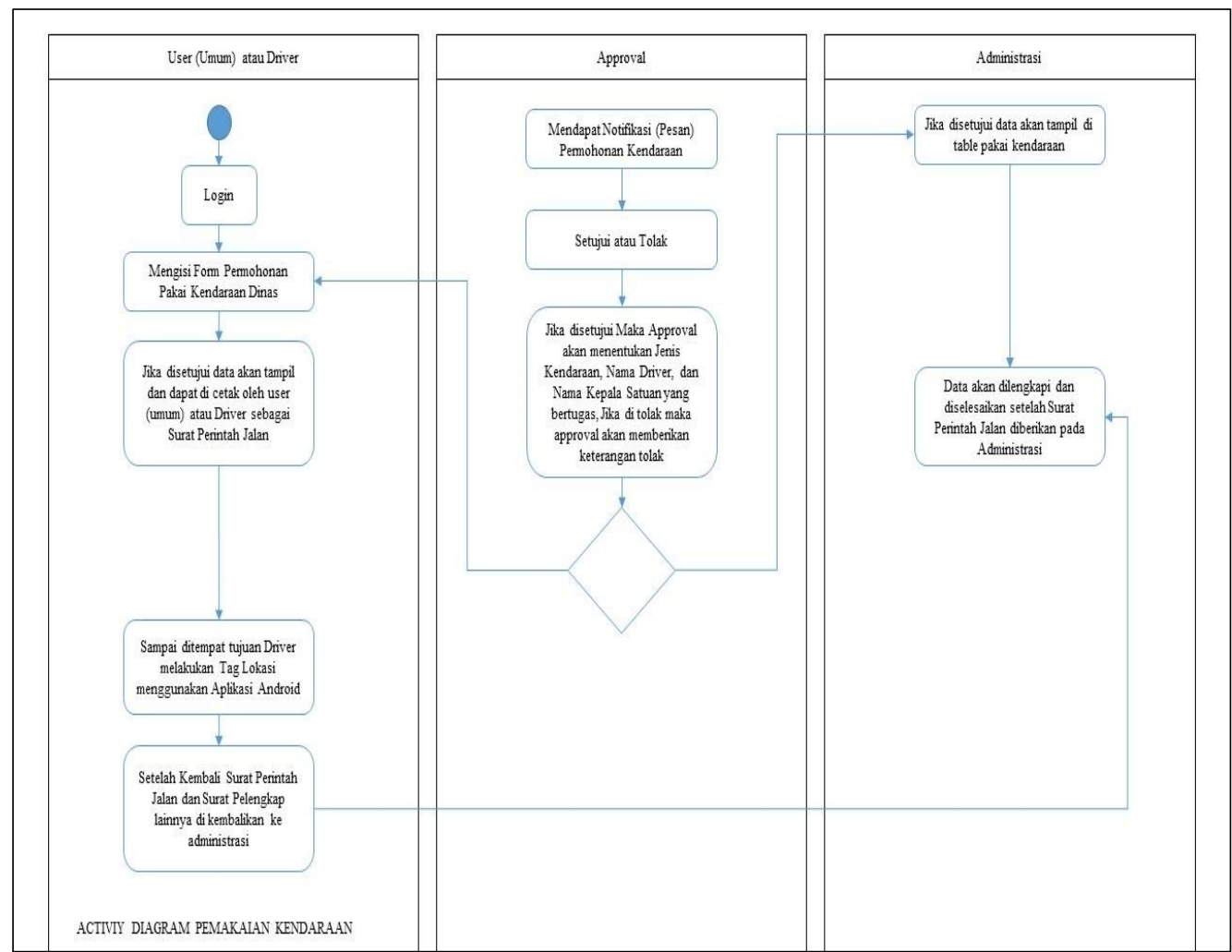

Gambar 5. Acitvity Diagram

\subsection{Manajemen Database}

3.4.1 Database Tabel User

Struktur data pada tabel user dapat di lihat pada tabel 1.

Tabel 1. Tabel User

\begin{tabular}{lllll}
\hline No & Elemen Data & Tipe & Values & Keterangan \\
\hline 1 & id & int & 11 & Primary Key \\
2 & username & varchar & 10 & \\
3 & pasw & varchar & 25 & \\
4 & fotouser & text & & \\
5 & nama_lengkap & varchar & 50 & \\
6 & nip_peg & varchar & 15 & \\
7 & jabatan & varchar & 18 & \\
8 & akses & int & 1 & \\
\hline
\end{tabular}

\subsubsection{Database Tabel Manager}

Struktur data pada tabel manager dapat di lihat pada tabel 2.

Tabel 2. Tabel Manager

\begin{tabular}{|c|c|c|c|c|}
\hline No & Elemen Data & Tipe & Values & Keterangan \\
\hline 1 & id & int & 11 & Primary Key \\
\hline 2 & nama_manajer & varchar & 35 & \\
\hline 3 & nip_manajer & int & 6 & \\
\hline 4 & jabatan & varchar & 25 & \\
\hline
\end{tabular}

\subsubsection{Database Tabel Unit}

Struktur data pada tabel unit dapat di lihat pada tabel 3. 
Tabel 3. Tabel Unit

\begin{tabular}{lllll}
\hline No & Elemen Data & Tipe & Values & Keterangan \\
\hline 1 & id & int & 11 & Primary Key \\
2 & units & varchar & 100 & \\
\hline
\end{tabular}

\subsubsection{Database Tabel Tempat Service}

Struktur data tabel tempat service dapat di lihat pada tabel 4.

Tabel4. Tabel Tempat_Service

\begin{tabular}{lllll}
\hline No & Elemen Data & Tipe & Values & Keterangan \\
\hline 1 & id & int & 11 & Primary Key \\
2 & nama bengkel & varchar & 50 & \\
\hline
\end{tabular}

\subsubsection{Database Tabel Keperluan}

Struktur data tabel keperluan dapat di lihat pada tabel 5.

Tabel 5. Tabel Keperluan

\begin{tabular}{lllll}
\hline No & Elemen Data & Tipe & Values & Keterangan \\
\hline 1 & id & int & 11 & Primary Key \\
2 & keperluan & varchar & 70 & \\
\hline
\end{tabular}

\subsubsection{Database Tabel Kendaraan}

Struktur data tabel kendaraan dapat di lihat pada tabel 6 .

Tabel 6. Tabel Kendaraan

\begin{tabular}{lllll}
\hline No & Elemen Data & Tipe & Values & Keterangan \\
\hline 1 & id & int & 11 & Primary Key \\
2 & jenis_kendaraan & varchar & 12 & \\
3 & merk_kendaraan & varchar & 6 & \\
4 & tipe_kendaraan & varchar & 15 & \\
5 & no_plat & varchar & 11 & \\
\hline
\end{tabular}

\subsection{Implementasi Sistem}

\subsubsection{Form Login}

Tampilan halaman login dapat dilihat pada gambar 6 .

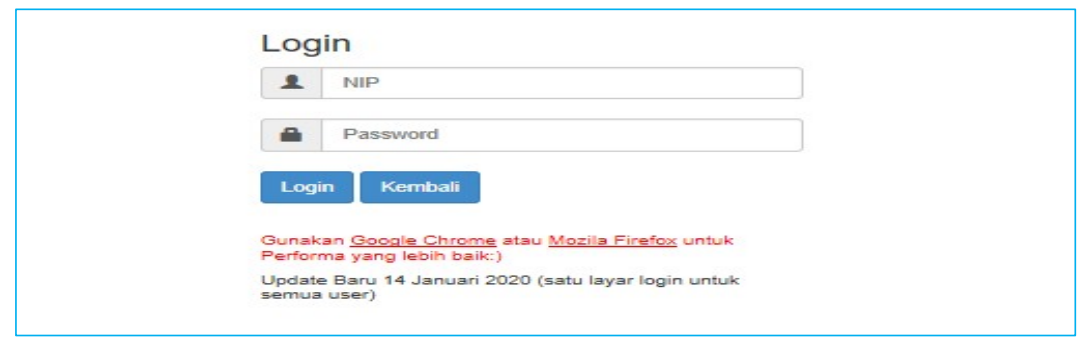

Gambar 6. Halaman Login

Setelah login semua pengguna akan di arahkan ke halaman utama sesuai dengan hak akses yang diberikan pada masing-masing pengguna.

\subsubsection{Form Permintaan Kendaraan Dinas}

Tampilan halaman permintaan kendaraan dinas pada pengguna dengan hak akses user dapat di lihat pada gambar 7. 


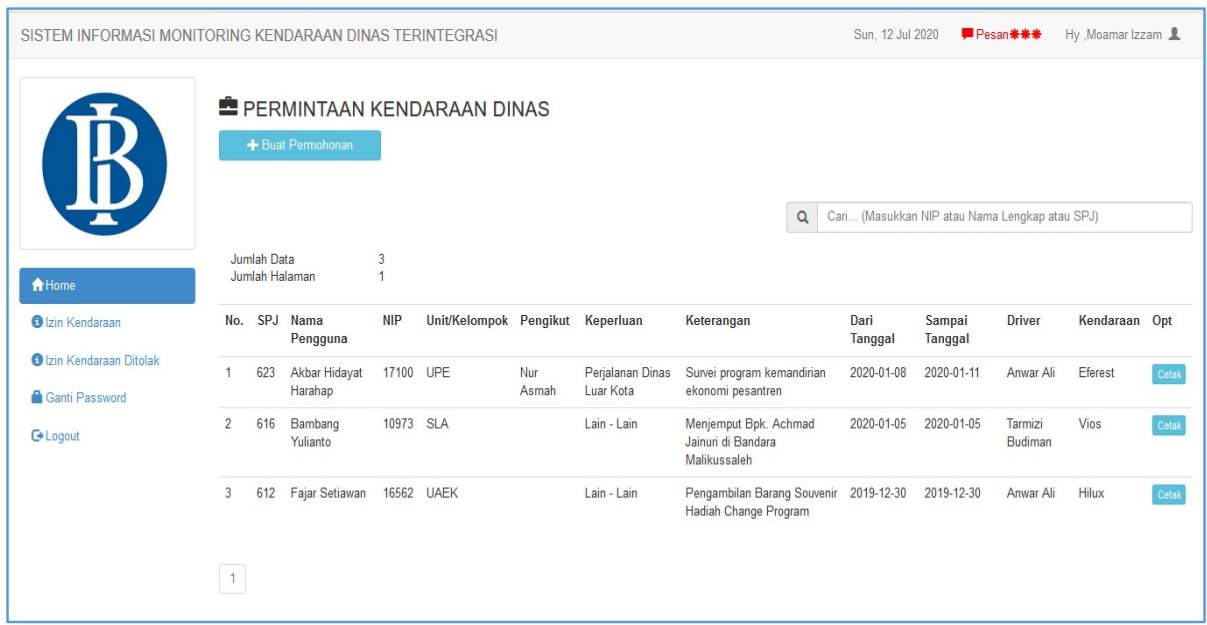

Gambar 7. Halaman Permintaan Kendaran Dinas

Pada Halaman permintaan kendaran dinas data permintaan kendaraan yang diajukan oleh pengguna dengan hak akses user dan telah disetujui oleh approval akan ditampilkan disini, selain itu juga terdapat tombol untuk membuat permohonan kendaraan dinas dan tombol untuk cetak yang berfungsi untuk mencetak surat izin penggunaan kendaraan dinas.

\subsubsection{Form Data Lokasi}

Tampilan halaman data lokasi yang di kirim oleh pengemudi (driver) di simpan secara online dah dapat di pastikan posisinya berdasarkan latitude dan longitude saat pengemui (driver) mengirimkan lokasinya seperti pada gambar 8 .

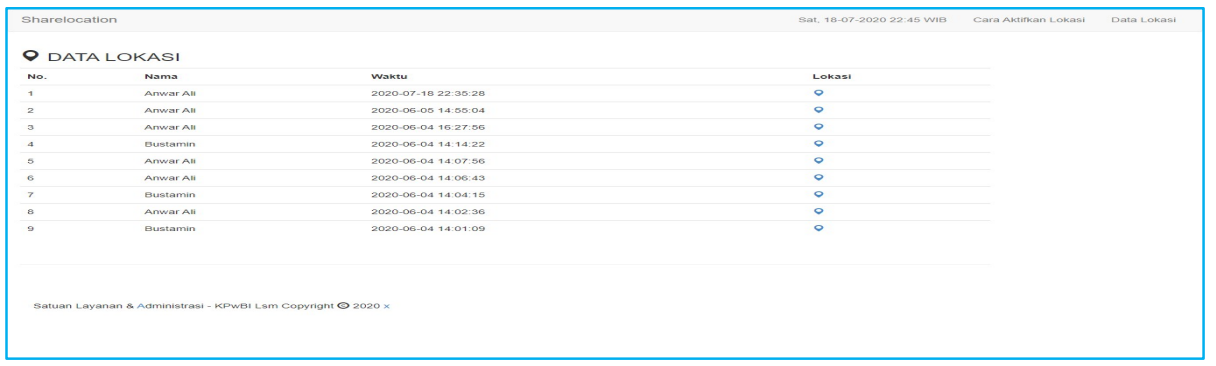

Gambar 8. Halaman Data Lokasi GPS

Berikut ini merupakan tampilan lokasi melalui Google Maps.

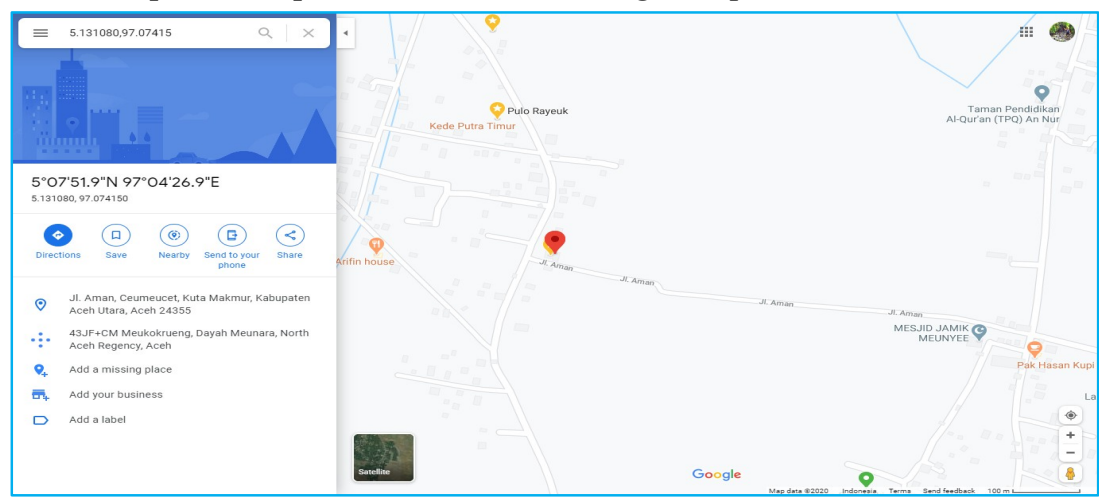

Gambar 9. Lokasi Dengan Google Map 


\subsection{Evaluasi Sistem}

Adapun evaluasi dari perancangan dan penerapan sistem informasi monitoring kendaraan dinas terintegrasi pada Bank Indonesia Lhokseumawe antara lain:

a. Tingkat kesiapan pengguna sangat baik.

b. Tingkat penerimaan user sangat baik.

c. Tingkat kepuasan pengguna sangat baik.

Dengan adanya implementasi sistem informasi ini sangat berdampak positif bagi kantor Bank Indonesia Lhokseumawe karena dengan sistem ini Kepala Unit dapat memonitoring kendaraan dinas secara real time. Sistem ini juga sangat efektif digunakan untuk memudahkan kegiatan adminitstrasi dan pemeliharaan kendaraan dinas.

\section{Conclusion}

Penerapan sistem informasi ini dapat memberikan kemudahan dalam memonitoring kendaraan dinas pada Bank Indonesia Lhokseumawe. Sistem informasi ini dapat membantu menampilkan laporan menjadi lebih mudah dan akurat karena sistem telah terintegrasi dengan database sehingga availability lebih terjamin. Kelebihan sistem ini antara lain:

a. Kontrol pengemudi dan kendaraan, memudahkan approval untuk mengatur jadwal serta memonitor data pengemudi dan kendaraan.

b. Memudahkan bagian administrasi untuk melihat dan membuat laporan pemakaian kendaraan, pembelian bahan bakar, dan biaya pemeliharan perbulan.

c. Aplikasi mampu memberikan pemberitahuan berupa pesan secara real time jika ada pengajuan pemakaian kendaraan.

d. Mampu melakukan computer generated value secara otomatis untuk penomoran setiap kode Surat Perintah Jalan (SPJ).

e. Sistem Informasi Kendaraan Dinas merupakan aplikasi berbasis web intranet, yang bisa di akses dari seluruh jaringan komputer di seluruh Kantor Bank Indonesia dalam negeri dan luar negeri.

Adapun saran dari penelitian ini adalah agar pembaca bisa mengembangkan sistem informasi monitoring kendaraan dinas dengan menambah algoritma kriptografi untuk keamanan akses data.

\section{References}

[1] Ariefni, Dhia Farida, and Mercurius Broto Legowo, "Penerapan Konsep Monitoring Dan Evaluasi Dalam Sistem Informasi Kegiatan Mahasiswa Di Perbanas Institute Jakarta," Jurnal Teknik Informatika dan Sistem Informasi vol 4, no.3, pp. 422-432, 2018.

[2] Dewi, Febriana, "Penerapan Sistem Informasi Monitoring Persediaan Barang Menggunakan Metode Fifo Berbabis Web (Studi Kasus: PT Indo Helmet Gallery),” Diss. Perpustakaan Teknokrat, 2018.

[3] Dinata, Rozzi Kesuma, "Sistem Informasi Pendataan Mahasiswa Kerja Praktek di Bank BRI Unit Cot Girek Kanca Lhokseumawe," INFORMAL: Informatics Journal vol 1, no.3, pp. 132-136, 2016.

[4] Hendini, Ade, "Pemodelan Uml Sistem Informasi Monitoring Penjualan Dan Stok Barang (Studi Kasus: Distro Zhezha Pontianak), " Jurnal Khatulistiwa Informatika vol 4. no.2, 2016.

[5] Herliana, Asti, and Prima Muhamad Rasyid, "Sistem Informasi Monitoring Pengembangan Software Pada Tahap Development Berbasis Web," Jurnal Informatika., vol 3. no.1, 2016.

[6] Junaidi, Junaidi, Ladyca Anugrah, and Adhitya Dwi Pancasakti, "Model Aplikasi Monitoring Sistem Absensi Sidik Jari Sebagai Pendukung Keputusan Untuk Penilaian Kinerja Pegawai," Proceedings Konferensi Nasional Sistem dan Informatika (KNS\&I), 2015.

[7] Megawati, Andi, and Dian Gustina, "Membangun Sistem Informasi Monitoring Kegiatan Proyek Pemancar Sinyal BTS Berbasis Web Pada PT. Swatama Mega Teknik," Jurnal Ilmiah Fifo vol 10, no.1, pp. 22-28, 2018.

[8] Novianta, Muhammad Andang, and Emy Setyaningsih, "Sistem Informasi Monitoring Kereta Api Berbasis Web Server Menggunakan Layanan GPRS," Jurnal Momentum., vol 17. no.2, 2015.

[9] Priyanto, Wenda, Didik Nugroho, and Bebas Widada, "Sistem Informasi Monitoring Perkuliahan Berbasis Web Di STMIK Sinar Nusantara Surakarta," Jurnal Teknologi Informasi dan Komunikasi (TIKomSiN), vol 3. no.1, 2015.

[10] Susanto, Eko Budi, Mohammad Reza Maulana, and Paminto Agung Christianto, "Penerapan Framework Codeigniter dan Library Ion Auth Pada Sistem Informasi Monitoring Penerima Beasiswa," IC-Tech vol 13, no.2, 2018. 